\title{
Accelerometer measured daily physical activity and sedentary pursuits-comparison between two models of the Actigraph and the importance of data reduction
}

Tina Tanha ${ }^{1,2}$, Åsa Tornberg ${ }^{1,3,4}$, Magnus Dencker ${ }^{1 *}$ and Per Wollmer ${ }^{1}$

\begin{abstract}
Background: Very few validation studies have been performed between different generations of the commonly used Actigraph accelerometers. We compared daily physical activity data generated from the old generation Actigraph model 7164 with the new generation Actigraph GT1M accelerometer in 15 young females for eight consecutive days. We also investigated if different wear time thresholds had any impact on the findings. Minutes per day of moderate and vigorous physical activity (MVPA), vigorous physical activity (VPA) and very vigorous physical activity (VPA) were calculated. Moreover, minutes of sedentary pursuits per day were calculated.

Findings: There were significant $(P<0.05)$ differences between the Actigraph 7164 and the GT1M concerning MVPA (61 \pm 21 vs. $56 \pm 23 \mathrm{~min} /$ day), VPA (12 \pm 8 vs. $9 \pm 3 \mathrm{~min} /$ day) and WPA ( $3.2 \pm 3.0 \mathrm{vs.} 0.3 \pm 1.1 \mathrm{~min} /$ day). The different wear time thresholds had little impact on minutes per day in different intensities. Median minutes of sedentary pursuits per day ranged from 159 to 438 minutes depending on which wear time threshold was used (i.e. 10, 30 or 60 minutes), whereas very small differences were observed between the two different models.

Conclusions: Data from the old generation Actigraph 7164 and the new generation Actigraph GT1M accelerometers differ, where the Actigraph GT1M generates lower minutes spent in free living physical activity. Median minutes of sedentary pursuits per day are highly dependent on which wear time threshold that is used, and not by accelerometer model.
\end{abstract}

Keywords: Accelerometers, Accelerometry, Validation study, Actigraph

\section{Findings}

Accelerometers are widely used for assessment of physical activity in childhood to old age [1-3]. They provide objective and detailed information on various aspects of physical activity [4-6]. The Actigraph is probably the most validated accelerometer on the market [6]. Validation studies have established appropriate cut-off points corresponding to different intensity levels for the old generation Actigraph 7164 [7,8]. Newer generations of the Actigraph have been introduced, and since accelerometers are increasingly used in research regarding

\footnotetext{
* Correspondence: magnus.dencker@skane.se

'Department of Clinical Sciences, Unit of Clinical Physiology and Nuclear Medicine, Skåne University Hospital, Lund University, Malmö, Sweden Full list of author information is available at the end of the article
}

physical activity and data output from older models are compared and used with newer models, it appears important to evaluate potential differences between different accelerometer generations. After the accelerometer data are collected there are different ways of analysing the data concerning wear time (i. e. if the accelerometer has been worn or not), unfortunately without consensus on how.

This study therefore aims to evaluate:

1. Possible differences between two types of accelerometers, an old generation Actigraph 7164 and a new generation Actigraph GT1M in daily physical activity measurements, including minutes of sedentary pursuits per day.

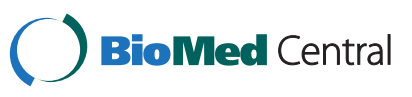

c 2013 Tanha et al.; licensee BioMed Central Ltd. This is an open access article distributed under the terms of the Creative Commons Attribution License (http://creativecommons.org/licenses/by/2.0), which permits unrestricted use, distribution, and reproduction in any medium, provided the original work is properly cited. 
2. The impact of different wear time thresholds on activity measurements.

\section{Methods}

A total of 15 females aged 18-32 years were investigated. The participants were soccer players from a local soccer team. Weight and height were measured, and BMI was calculated. The study was approved by the Regional ethical review board at Lund, and performed according to the Helsinki Declaration. Written consent was obtained from the participants. Both accelerometers (Actigraph 7164 and Actigraph GT1M, Actigraph inc., Pensacola, FL) were worn side-by-side around the waist for eight consecutive days. The participants were instructed to use the accelerometer during waking hours and only remove it during activities that could damage the accelerometer (water based activities). A recording epoch of 60 seconds was selected for this study. Eight hours of valid recording was considered an acceptable day [2].

Accelerometer data were assessed in ActiLife 5.10.0 (Actigraph inc., Pensacola, FL). Minutes per day of moderate and vigorous physical activity (MVPA), vigorous physical activity (VPA) and very vigorous physical activity (VVPA) were calculated. Moreover, minutes of sedentary pursuits per day were calculated. Sedentary pursuits were defined as $<100$ counts per min (cpm) [9], MVPA as $>1952$, VPA as $>5725$ and VVPA as $>9499 \mathrm{cpm}[7,8]$. Three different wear time thresholds were applied with the software from the manufacturer with threshold values: 10, 30 and 60 minutes (defined as 10, 30 or 60 minutes of consecutive zeros in the accelerometer data). Thus, if 10 minutes of wear time threshold was used, it meant that all data during the 10 minutes of consecutive zeros were deleted. We also performed an additional analysis with allowance of 2 minutes of sporadic activity counts.

Statistica 10 (StatSoft Inc, Tulsa, OK, USA) was used for all statistical analyses. Descriptive data are presented as mean $\pm \mathrm{SD}$ and accelerometer data as median $\pm \mathrm{IQR}$ (interquartilrange). Differences between medians for the Actigraph 7164 and the Actigraph GT1M were tested with the Wilcoxon matched pairs test. A ratio between data from Actigraph 7164 and the Actigraph GT1M was calculated.

\section{Results}

The participants were $23.7 \pm 4$ years (mean \pm SD), body mass $65 \pm 6 \mathrm{~kg}$, height $171 \pm 4 \mathrm{~cm}$ and BMI $22 \pm 1 \mathrm{~kg} / \mathrm{m}^{2}$. All participants had eight acceptable recording days [2]. Consistently lower median minutes per day spent in all different physical activity levels were found for Actigraph GT1M compared to Actigraph 7164, where the relative difference was higher at higher intensities (i. e. VPA and VVPA). Median minutes of sedentary pursuits per day ranged from 159 to 438 minutes depending on which wear time threshold was used (i.e. 10, 30 or 60 minutes), whereas very small differences were observed between the two different models. Table 1 summarises the accelerometer findings. Incorporation of 2 minute segments of sporadic activity during the wear time threshold did not have any major impact on the results with the exception that the differences for VPA failed to reach statistical significance (data not shown).

\section{Discussion}

This was a comparison between old generation Actigraph model 7164 and new generation Actigraph GT1M in freeliving physical activity. The new generation Actigraph GT1M showed consistently lower median minutes per day for the investigated intensities, whereas small differences were observed for time in sedentary pursuits. Different wear time thresholds had no effect on minutes in different physical activity intensities. In contrast, time in sedentary pursuits was dependent on which wear time threshold that was used.

There are only a few studies in this field [10,11], and the findings are diverging. has previously compared the GT1M and 7164 during treadmill testing and found significant differences ranging from 10 to $23 \%$ between the models [12]. Corder et al. also compared the Actigraph

Table 1 Comparison between the old Actigraph model 7164 and the new Actigraph GT1M depending on wear time threshold (i.e. 10, 30 or 60 minutes wear time), values are median \pm IQR (interquartile range)

\begin{tabular}{|c|c|c|c|c|}
\hline \multicolumn{5}{|l|}{10 min wear time } \\
\hline & Mod 7164 & GT1M & P-value & 7164/ GT1M \\
\hline Sedentary (<100 cpm) & $184 \pm 50$ & $159 \pm 36$ & 0.12 & 1.16 \\
\hline MVPA (>1952 cpm) & $61 \pm 20$ & $56 \pm 23$ & 0.01 & 1.09 \\
\hline VPA (>5725 cpm) & $12 \pm 8$ & $9 \pm 3$ & 0.002 & 1.33 \\
\hline WPA (>9499 cpm) & $3.2 \pm 3.0$ & $0.3 \pm 1.1$ & $<0.001$ & 10.67 \\
\hline \multicolumn{5}{|l|}{30 min wear time } \\
\hline & Mod 7164 & GT1M & P-value & 7164/ GT1M \\
\hline Sedentary (<100 cpm) & $337 \pm 76$ & $331 \pm 64$ & 1.0 & 1.02 \\
\hline MVPA (>1952 cpm) & $61 \pm 21$ & $56 \pm 23$ & 0.01 & 1.09 \\
\hline VPA (>5725 cpm) & $12 \pm 8$ & $9 \pm 3$ & 0.002 & 1.33 \\
\hline WPA (>9499 cpm) & $3.2 \pm 3.0$ & $0.4 \pm 1.1$ & $<0.001$ & 8.00 \\
\hline \multicolumn{5}{|l|}{60 min wear time } \\
\hline & Mod 7164 & GT1M & P-value & 7164/ GT1M \\
\hline Sedentary(<100 cpm) & $429 \pm 64$ & $438 \pm 53$ & 0.01 & 0.98 \\
\hline MVPA (>1952 cpm) & $61 \pm 21$ & $56 \pm 23$ & 0.01 & 1.09 \\
\hline VPA (>5725 cpm) & $12 \pm 8$ & $9 \pm 3$ & 0.002 & 1.33 \\
\hline WPA (>9499 cpm) & $3.2 \pm 3.0$ & $0.4 \pm 1.1$ & $<0.001$ & 8.00 \\
\hline
\end{tabular}

Moderate and vigorous physical activity (MVPA), vigorous physical activity (VPA) and very vigorous physical activity (VPA). The ratio between median data output of 7164 and GT1M is also expressed. 
model 7164 with the Actigraph GT1M [9]. Free-living daily activity was measured with both models for seven days, however in contrast to this study their population consisted of 15-16 year old teenagers. Their results indicated no significant differences between the different models for time spent in moderate or vigorous physical activity [10]. However, time performing light activity was 9\% lower with the Actigraph GT1M. In contrast to Corder et al. we observed daily physical activity values for all intensities [10]. One suggestion to why data output between the Actigraph models differ more at low intensities than high intensity is that accelerometer counts tend to reach a plateau, which has previously been described $[13,14]$. Moreover, John et al. compared the Actigraph (GT1M and 7164) during a treadmill test in ten endurance trained men (ages $23 \pm 3$ ) and concluded no significant differences between the different models [11]. In contrast, the results of this study suggest differences in Accelerometer output between Actigraph 7164 and GT1M. One feasible explanation can be the technical differences between Actigraph 7164 and GT1M regarding band pass filtering and sampling frequency $[14,15]$. The new Accelerometers have more advanced electronic properties, for example the GT1M digitizes the accelerometer output by a 12-bit analog to digital converter at $30 \mathrm{Hertz}$ in comparison to 7164 that digitize by 8-bit analog to digital converter at 10 Hertz [16]. These differences may result in the differences found in data output between the two models. Regardless of the reason we conclude that previous data from validation and fieldbased studies from old generation Actigraph models may not be interchangeable. It is therefore important to generate new validation studies with the new generation accelerometers since the present validation studies and cut-off points are mainly carried out with the old generation accelerometers [6-8]. The diverging findings between studies also indicate need for large-scale comprehensive validation studies. The differences between the different Actigraph models seem to be between 7164 and GT1M, as two recent studies have not shown any differences between the GT1M and the GT3X $[17,18]$ and during uniaxial setting [19]. Ried-Larsen et al compared 7164 with GT3X in a free living setting with a population of 20 (mean age 37.8) and found significant differences in data output between the monitors [17]. They did not compare 7164 with GT1M in a free living setting, which differs from our study. However, there was a significant difference between 7164 and GT1M in the mechanical setup.

There has in recent years also been an increased interest in health-related implications specifically associated with sedentary pursuits [9,20-22]. A small difference (mean output ratio $7164 /$ GT1M $=0.95$ ) was seen when 60 minute wear time threshold was used in median minutes of sedentary pursuit between the models. No significant differences were observed when 10 or 30 minute wear time thresholds were used. It is difficult to say why no differences occurred between the models when measuring $<100 \mathrm{cpm}$ in contrast to activities $>1952 \mathrm{cpm}$, but one line of reasoning may be that the absolute values $<100$ are so small that it requires very large differences to obtain significance. However the analyses of different wear time thresholds showed that there was almost a threefold difference in minutes of sedentary pursuits per day between the lowest threshold value $10 \mathrm{~min}$ and the highest threshold value $60 \mathrm{~min}$. The reasonable explanation is that selection of a higher wear time threshold will presumably result in time that the accelerometer is not worn being misinterpreted as sedentary pursuits. There is, however, no consensus whether to delete missing data or not. Many early studies did not report deletion of missing data and probably did not do it. Several investigators have used the practice of deleting missing data defined as 10 minutes of zeros [23-26], some have defined missing data as 20 minutes of zeros [27], and some have used one hour with allowance of sporadic episodes of low counts [28]. A completely different approach of replacing missing data with various type estimates has also been suggested [29], which is somewhat questionable since it makes the assumption that episodes that the monitor is not worn represent average physical activity. This assumption is highly dependent on whether the monitor was simply forgotten, or taken off because of a certain activity such as for example swimming. There are some studies [30-32] that have examined correlations of different wear time thresholds and agree that time spent in sedentary pursuit is effected by which type of wear time threshold is used. However, wear time threshold has no or small influence on MVPA. Instead, it seems that increasing the wear time threshold decreases the average activity count per minute. There are multiple algorithms suggested to improve the quality of accelerometer data, one being allowance of 2 minute segments during the wear time threshold [28,33]. This analysis was performed in this study and did not have any major impact on the results.

Limitation of this study includes the low number of participants, which may influence power. This was, however, a pilot study. Additional limitations were that only females were investigated and that we did not have access to a gold standard (i.e. indirect calorimetry).

\section{Conclusion}

The older generation Actigraph 7164 consistently generates lower median minutes spent in MVPA, VPA and VVPA compared to Actigraph GT1M in a free living physical activity setting. Accelerometer model does not influence median minutes of sedentary pursuit, instead differences are dependent on which wear time threshold is used. 


\section{Competing interests}

The authors declare that they have no competing interests.

\section{Authors' contributions}

All authors made substantial contributions to conception and design. ÅT and $\Pi$ made substantial contributions to acquisition of data. $\Pi$, $\AA$ T and MD made substantial contributions to analysis and interpretation of data. TT, MD and PW made substantial contributions to drafting the article. All authors made substantial contributions to revising it critically for important intellectual content and gave final approval of the version to be published.

\section{Acknowledgements}

This work was supported by Lund University, Malmö Sports Acadamy and Region Skåne grants.

\section{Author details}

${ }^{1}$ Department of Clinical Sciences, Unit of Clinical Physiology and Nuclear Medicine, Skåne University Hospital, Lund University, Malmö, Sweden. ${ }^{2}$ Department of Cardiology, Heart Failure and Valvular Disease, Skåne University Hospital, Lund University, Malmö, Sweden. ${ }^{3}$ Department of Health Sciences, Physiotherapy, Lund University, Malmö, Sweden. ${ }^{4}$ Department of Clinical Sciences, Genetic \& Molecular Epidemiology Unit, Lund University Diabetes Center, Skåne University Hospital, Malmö, Sweden.

Received: 22 March 2013 Accepted: 29 October 2013

Published: 31 October 2013

\section{References}

1. Troiano RP: A timely meeting: objective measurement of physical activity. Med Sci Sports Exerc 2005, 37(Suppl 11):S487-S489.

2. Dencker M, Svensson J, El-Naaman B, Bugge A, Andersen LB: Importance of epoch length and registration time on accelerometer measurements in younger children. J Sports Med Phys Fitness 2012, 52:115-121.

3. Dencker $M$, Andersen LB: Accelerometer-measured daily physical activity related to aerobic fitness in children and adolescents. J Sports Sci 2011, 29:887-895.

4. Trost SG: Objective measures of physical activity with youth: current issues, future directions. Exerc Sport Sci Rev 2001, 29:32-36.

5. Plasqui G, Westerterp KR: Physical activity assessment with accelerometers: an evaluation against doubly labeled water. Obesity (Silver Spring) 2007, 15:2371-2379.

6. Dencker M, Andersen LB: Health related aspects of objectively measured daily physical activity in children. Clin Physiol Funct Imaging 2008, 28:133-144.

7. Freedson PS, Melanson E, Sirard J: Calibration of the computer science and applications, Inc. accelerometer. Med Sci Sports Exerc 1998, 30:777-781.

8. Matthew CE: Calibration of accelerometer output for adults. Med Sci Sports Exerc 2005, 37(11 Suppl):S512-S522.

9. Matthews CE, Chen KY, Freedson PS, Buchowski MS, Beech BM, Pate RR, Troiano RP: Amount of time spent in sedentary behaviors in the United States, 2003-2004. Am J Epidemiol 2008, 167:875-881.

10. Corder K, Brage S, Ramachandran A, Snehalatha C, Wareham N, Ekelund U: Comparison of two Actigraph models for assessing free-living physical activity in Indian adolescents. J Sports Sci 2007, 25:1607-1611.

11. John D, Tyo B, Bassett DR: Comparison of four ActiGraph accelerometers during walking and running. Med Sci Sports Exerc 2010, 42:368-374.

12. Tanha T, Tornberg ÅB, Wollmer P, Dencker M: Head-to-head comparison between Actigraph 7164 and GT1M accelerometers in adolescents. Clin Physiol Funct Imaging 2013, 33:162-165.

13. Brage S, Wedderkorp N, Franks PW, Andersen LB, Froberg K: Reexamination of validity and reliability of the CSA monitor in walking and running. Med Sci Sports Exerc 2003, 35:1447-1454.

14. Fudge BW, Wilson J, Easton C, Irwin L, Clark J, Haddow O, Kayser B, Pitsiladis YP: Estimation of oxygen uptake during fast running using accelerometry and heart rate. Med Sci Sports Exerc 2007, 39:192-198.

15. Rothney MP, Apker GA, Song Y, Chen KY: Comparing the performance of three generations of ActiGraph accelerometers. J Appl Physiol 2008, 105:1091-1097.

16. LLC: ActiGraph. 2013.

17. Ried-Larsen M, Brønd JC, Brage S, Hansen BH, Grydeland M, Andersen LB, Møller NC: Mechanical and free living comparisons of four generations of the Actigraph activity monitor. Int J Behav Nutr Phys Act 2012, 9:113.
18. Vanhelst J, Mikulovic J, Bui-Xuan G, Dieu O, Blondeau T, Fardy P, Béghin L: Comparison of two ActiGraph accelerometer generations in the assessment of physical activity in free living conditions. BMC Res Notes 2012, 5:187.

19. Sasaki JE, John D, Freedson PS: Validation and comparison of ActiGraph activity monitors. J Sci Med Sport 2011, 14:411-416.

20. Hamilton MT, Hamilton DG, Zderic TW: Role of low energy expenditure and sitting in obesity, metabolic syndrome, type 2 diabetes, and cardiovascular disease. Diabetes 2007, 56:2655-2667.

21. Hamilton MT, Healy GN, Dunstan DW, Zderic TW, Owen N: Too little exercise and too much sitting: inactivity physiology and the need for new recommendations on sedentary behavior. Curr Cardiovasc Risk Rep 2008, 2:292-298.

22. Owen N, Healy GN, Matthews CE, Dunstan DW: Too much sitting: the population health science of sedentary behavior. Exerc Sport Sci Rev 2010, 38:105-113.

23. Riddoch CJ, Andersen LB, Wedderkopp N, Harro M, Klasson-Heggebø L, Sardinha LB, Cooper AR, Ekelund U: Physical activity levels and patterns of 9-and 15-year-old European children. Med Sci Sports Exerc 2004, 36:86-92.

24. Dencker M, Bugge A, Hermansen B, Andersen LB: Objectively measured daily physical activity related to aerobic fitness in young children. J Sports Sci 2010, 28:139-145.

25. Dencker M, Thorsson O, Karlsson MK, Lindén C, Svensson J, Wollmer P, Andersen LB: Daily physical activity in Swedish children aged 8-11 years. Scand J Med Sci Sports 2006, 16:252-257.

26. Baquet G, Stratton G, Van Praagh E, Berthoin S: Improving physical activity assessment in prepubertal children with high-frequency accelerometry monitoring: a methodological issue. Prev Med 2007, 44:143-147.

27. Treuth MS, Sherwood NE, Baranowski T, Butte NF, Jacobs DR Jr, McClanahan B, Gao S, Rochon J, Zhou A, Robinson TN, Pruitt L, Haskell W, Obarzanek E: Physical activity self-report and accelerometry measures from the girls health enrichment multi-site studies. Prev Med 2004, 38(Suppl):S43-S49.

28. Troiano RP, Berrigan D, Dodd KW, Mâsse LC, Tilert T, McDowell M: Physical activity in the United States measured by accelerometer. Med Sci Sports Exerc 2008, 40:181-188.

29. Catellier DJ, Hannan PJ, Murray DM, Addy CL, Conway TL, Yang S, Rice JC: Imputation of missing data when measuring physical activity by accelerometry. Med Sci Sports Exerc 2005, 37(11 Suppl):S555-S562.

30. Winkler EAH, Gardiner PA, Clark BK, Matthews CE, Owen N, Healy GN: Identifying sedentary time using automated estimates of accelerometer wear time. Br J Sports Med 2012, 46:436-442.

31. Evenson KR, Terry JW Jr: Assessment of differing definitions of accelerometer nonwear time. Res Q Exerc Sport 2009, 80:355-362.

32. Choi L, Liu Z, Matthews CE, Buchowski MS: Validation of accelerometer wear and nonwear time classification algorithm. Med Sci Sports Exerc 2011, 43:357-364.

33. Ekelund U, Luan J, Sherar LB, Esliger DW, Griew P, Cooper A, International Children's Accelerometry Database (ICAD) Collaborators: Moderate to vigorous physical activity and sedentary time and cardiometabolic risk factors in children and adolescents. JAMA 2012, 307:704-712.

\section{doi:10.1186/1756-0500-6-439}

Cite this article as: Tanha et al:: Accelerometer measured daily physical activity and sedentary pursuits-comparison between two models of the Actigraph and the importance of data reduction. BMC Research Notes 2013 6:439

\section{Submit your next manuscript to BioMed Central and take full advantage of:}

- Convenient online submission

- Thorough peer review

- No space constraints or color figure charges

- Immediate publication on acceptance

- Inclusion in PubMed, CAS, Scopus and Google Scholar

- Research which is freely available for redistribution 